\title{
FUEGO DE ARTIFICIO
}

Giulio Cesare Capaccio, en Delle Imprese Trattato [1592], nos presenta esta empresa correspondiente a un tal Giovan Battista Crispo, cuya pictura consta de un cohete -dal Folgore (che noi diciamo)-, que asciende por el aire propulsado por el fuego, con el mote: QVANTUM NON NOXIA CORPORA TARDANT, que la prof. Beatriz Antón nos traduce como: "porque no los retardan cuerpos nocivos", advirtiendo también que se trata de un mote procedente de Virgilio (Aen. 6, 731), aunque ligeramente alterado en cuanto al orden de las palabras. ${ }^{1}$ Esta empresa es explicada por Capaccio en el sentido de querer manifestar un arduo y difícil empeño, el cual se logra en virtud del fuego de su interior, por cuya virtud el cohete se eleva en el aire cuando no lo impide -o «retarda», de acuerdo con el mote- ningún obstáculo material, como el querer imitar en lugar de ser parangón.

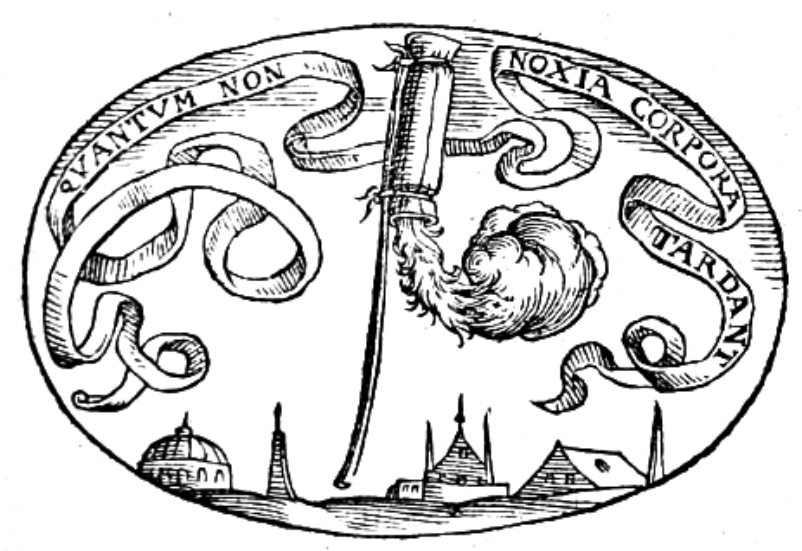

"[...] e volea per questo far conoscere vn'ardua, e difficile pretendenza; che già tanto quel fuogo iui nascosto ascende, quanto non troua impedimento dalla materia che'l fomenta, col volere imitare. Per questo sarà sempre lodevole far le nuoue, eccetto quando poco spirito hauessero le prime».

1. En su contexto, se trata del descenso de Eneas al Hades en el momento en que su padre Anquises le explica cada cosa: igneus est ollis uigor et caelestis origo seminibus, quantum non noxia corpora tardant terrenique hebetant artus moribundaque membra [ígneo es el vigor y el origen celeste de aquellas semillas, en cuanto que no las retardan cuerpos nocivos ni las entorpecen articulaciones terrenales ni miembros que han de morir] (Aen 6, 730-732). 
Por medio de una lectura reactualizada de esta empresa, quisiéramos explicar también un aspecto importante que afecta a nuestra revista: los esfuerzos que están haciendo algunas personas de cara a la elevación del reconocimiento de la calidad de IMAGo. En este sentido, debe ser reconocida la dedicación realizada por los profesores Rafael Zafra Molina, Elena Monzón Pertejo y Sergi Doménech García. Gracias a estos esfuerzos, la revista ha llegado a ser indexada últimamente por Erihplus y Latindex, mientras que Thomson Reuters nos ha comunicado que están valorando la posible indexación tras haber incluido IMAGo entre las revistas emergentes. Por lo tanto, podemos entender que el ascenso de nuestra revista es evidente y constante. El espíritu propulsor de este ascenso no es otro que el conjunto de autores que han publicado sus aportaciones en los diferentes números. Este espíritu está significado mediante el fuego, en virtud del cual el cohete de Capaccio se abre paso por los aires (Folgore che ascende in aria).

Esta empresa nos inspira también otra clase reflexión a nivel teórico, que no está tampoco de más. Este recurso al cohete es un claro "artificio retórico», o bien un "artificio conceptuoso» -término éste, más acorde con teóricos como Gracián, autor de Agudeza y arte de ingenio-, denominaciones ambas más adecuadas, probablemente, para referirnos a la agudeza emblemática, que el término «símbolo», que impropiamente está generalizado entre muchos estudiosos que lo han incorporado a su léxico usual. Aunque en muchas ocasiones los artificios de la emblemática -como fenómeno cultural expresado dentro de la retórica- puedan coincidir con auténticos «símbolos», es decir signos perennes en la tradición cultural que han servido para vehicular complejos argumentos relativos a lo especulativo, o incluso a lo sagrado -el círculo para significar el Cielo, la esfera para el Cosmos, o el pelícano para la Redención-, en el fondo, en el terreno de la emblemática, por la propia esencia y fines de ésta, no cabe realmente hablar tanto de "símbolo», sino más bien de aquella clase de recursos clasificables dentro del ornatus retórico, como pueden ser, entre otros, las metáforas o las alegorías. Claro, todo ello independientemente de que los mismos contemporáneos rubricasen estos remedios como «símbolos» -p. ej. en el mismo título de la obra Mondo Simbolico de Picinelli-, pero que hoy, con la complejidad que ha llegado a adquirir este término a partir de las reflexiones de los teóricos de los siglos XIX y XX (Creuzer, Hegel, Warburg, Cassirer o Durand) resulta el "símbolo» un término nítidamente diferente y de ningún modo confundible como un simple recurso de la retórica, bien sea ésta verbal o visual.

En la presente edición de IMAGo, se ofrecen principalmente una selección de las aportaciones realizadas en el X Congreso Internacional de la Sociedad Española de emblemática, celebrado en Málaga en otoño de 2013 y que, por tanto, han tenido que pasar por una doble selección: la propia del Congreso, más la revisión por pares de la revista. Se aportan también otros estudios particulares que han sido seleccionados y evaluados por el procedimiento ordinario. 